\title{
VOCs Destruction by Plasma Catalyst Coupling Using AL-KO PURE Air Purifier on Industrial Scale
}

\author{
Zixian Jia $^{{ }^{*}}$, Christelle Barakat ${ }^{1}$, Binjie Dong2 ${ }^{2}$, Antoine Rousseau ${ }^{1}$ \\ ${ }^{1}$ Laboratoire de Physique des Plasmas, Ecole Polytechnique, UPMC, Universite Paris Sud 11, CNRS, Palaiseau, \\ France \\ ${ }^{2} \mathrm{R} \& \mathrm{D}$ Department of AL-KO Therm GmbH, Jettingen-Scheppach, Germany \\ Email: ${ }^{*}$ zixian.jia@lpp.polytechnique.fr
}

Received April 2015

\begin{abstract}
We have investigated in this study the destruction of acetone and toluene with AL-KO PURE air purifier (AL-KO PURE) on industrial scale. In the case of acetone, $100 \%$ pollutant abatement is achieved with AL-KO PURE over more than 80 hours (the test duration time) at the high level concentration of $0.5 \mathrm{ppm}\left(1187 \mu \mathrm{g} / \mathrm{m}^{3}\right.$, about 7 times higher than the average living room level). This corresponds to $0.2 \mu \mathrm{mol} / \mathrm{s}$ with a flow rate of $38.42 \mathrm{~m}^{3} / \mathrm{h}$. The regeneration of a saturated catalytic filter was also tested. When the catalytic filter of AL-KO PURE is fully saturated with acetone, a $100 \%$ acetone destruction efficiency can be achieved at $0.46 \mathrm{ppm}$ concentration with $25 \%$ fan speed. Moreover the second pollutant, toluene, has been also studied. $100 \%$ toluene abatement also is achieved with AL-KO PURE over more than 80 hours (the test duration time) at the high level concentration of $0.2 \mathrm{ppm}\left(811 \mu \mathrm{g} / \mathrm{m}^{3}, 0.087 \mu \mathrm{mol} / \mathrm{s}\right.$ with a flow rate of $\left.38.42 \mathrm{~m}^{3} / \mathrm{h}\right)$. Finally, the availability for the simultaneous removal of both pollutants, acetone and toluene, has been also studied.
\end{abstract}

\section{Keywords}

Indoor Air, Plasma Technology, VOCs Removal, Plasma-Catalyst Coupling

\section{Introduction}

Indoor air pollution presents an increasing domestic environmental concern [1], because people in developed countries spend the majority of their time indoors, and the indoor air is often more polluted than outdoor air [2]. A large proportion of indoor air pollution originates from sources located inside the building, such as adhesives, carpeting, wood products and cleaning products, which may emit gaseous pollutants such as volatile organic compounds (VOCs) [3]. According to the European Union (EU), a VOC is defined as an organic compound having a boiling point lower than or equal to $523 \mathrm{~K}$ measured at atmospheric pressure. Hundreds of VOCs can

\footnotetext{
${ }^{*}$ Corresponding author.

How to cite this paper: Jia, Z.X., Barakat, C., Dong, B.J. and Rousseau, A. (2015) VOCs Destruction by Plasma Catalyst Coupling Using AL-KO PURE Air Purifier on Industrial Scale. Journal of Materials Science and Chemical Engineering, 3, $19-26$. http://dx.doi.org/10.4236/msce.2015.36004
} 
be simultaneously found in indoor air. Adverse health responses by VOCs, depending on length of exposure and VOCs concentration, in nonindustrial indoor environments include irritant effects resulting from mucous membrane irritation, systemic effects such as fatigue, the difficulty of concentrating and the toxic effects such as carcinogenicity.

As one of the VOCs, Acetone is a common household toxic chemical that may reduce your indoor air quality after being released from products such as paint, nail polish, secondhand cigarette smoke, and many household chemical products. The indoor acetone concentration is different depending on house surface, furniture numbers, ventilation, smoking or not and so on. For example, in Canada [4] the concentration median of acetone is 173.8 $\mu \mathrm{g} / \mathrm{m}^{3}$ in a range of $0.01-3755.5 \mu \mathrm{g} / \mathrm{m}^{3}$ in summer. While In China [5], during summer acetone concentrations are respectively 21.3, 16.5, 15.9 and $10.2 \mu \mathrm{g} / \mathrm{m}^{3}$ in Beijing, Shanghai, Xi'an, and Guangzhou. Average indoor air concentrations of toluene vary between 5 and 50 ppbv, with maximum concentrations up to 9 ppm [6]. Exposure to toluene has been shown to cause eye, nose, and throat irritation as well as headaches, dizziness, feelings of intoxication [7], and neurological effects [8]

For the abatement of dilute VOCs, with concentrations hardly exceeding $0.1 \mathrm{ppm}$, conventional techniques like thermal and thermo-catalytical oxidation are not suitable, mainly due to their high-energy consumption [9]. The treatment of polluted air streams containing VOCs by non-thermal plasma (NTP) is an alternative to conventional techniques, especially for low hydrocarbon concentrations. Heterogeneous plasma-catalysis is a promising strategy for remediating indoor air pollutants and has received considerable attention as a means of degrading volatile organic compounds (VOCs) [10]-[12] found indoors.

In this study, the efficiency of the AL-KO PURE in terms of acetone and toluene plasma-catalytic oxidation on industrial scale was investigated.

\section{Experimental Setup and Quantification Methodology}

\subsection{AL-KO PURE}

A general scheme of the experimental setup is reported in Figure 1(a). This setup can be divided into three main parts: (i) gas phase preparation; (ii) air purification device: AL-KO PURE (Figure 1(b)); (iii) analytical devices: UV analyzer and Fourier transform infrared spectroscopy (FTIR).

In order to accurately measure the inlet and outlet VOC concentration, the system was adjusted to inject a specific inlet VOC concentration using the condenser/saturator system and to measure the VOC level, by means of FT-IR before and after the treatment unit (AL-KO PURE), i.e. at the positions In and Out, as shown in part (ii) of Figure 1(a). The photo of AL-KO PURE reactor is shown in Figure 1(b), and it consists of 1) Inlet flow; 2) Filtration box; 3) Introduction of VOC in air flow; 4) Air sample sent to FT-IR before treatment; 5) AL-KO PURE treatment unit; 6) Air sample sent to FT-IR after treatment; 7) Pure air release for ventilation. More details of this reactor could be found in [13] [14]. The unit operates at room temperature and atmospheric pressure and normal relative humidity. The flow rate can go up to $257 \mathrm{~m}^{3} / \mathrm{h}$ and is regulated with a fan speed, as shown in Table 1.

\subsection{Gas Flow Preparation and Materials}

The ambient air is filtrated firstly through the Filtration box to remove the particles. Then it is flowing through

Table 1. Flow rate as a function of different fan speeds for AL-KO PURE.

\begin{tabular}{ccc}
\hline Fan speed & Flow rate & $\mathrm{m}^{3} / \mathrm{h}$ \\
\hline$\%$ & 38.42 & 0.40 \\
50 & 97.9 & 0.10 \\
75 & 172.35 & 0.03 \\
100 & 257.49 & 0.01 \\
\hline
\end{tabular}

${ }^{*}\left[\mathrm{O}_{3}\right]$ ozone concentration was measured without catalysts and with catalysts no ozone has been detected at the reactor output. 


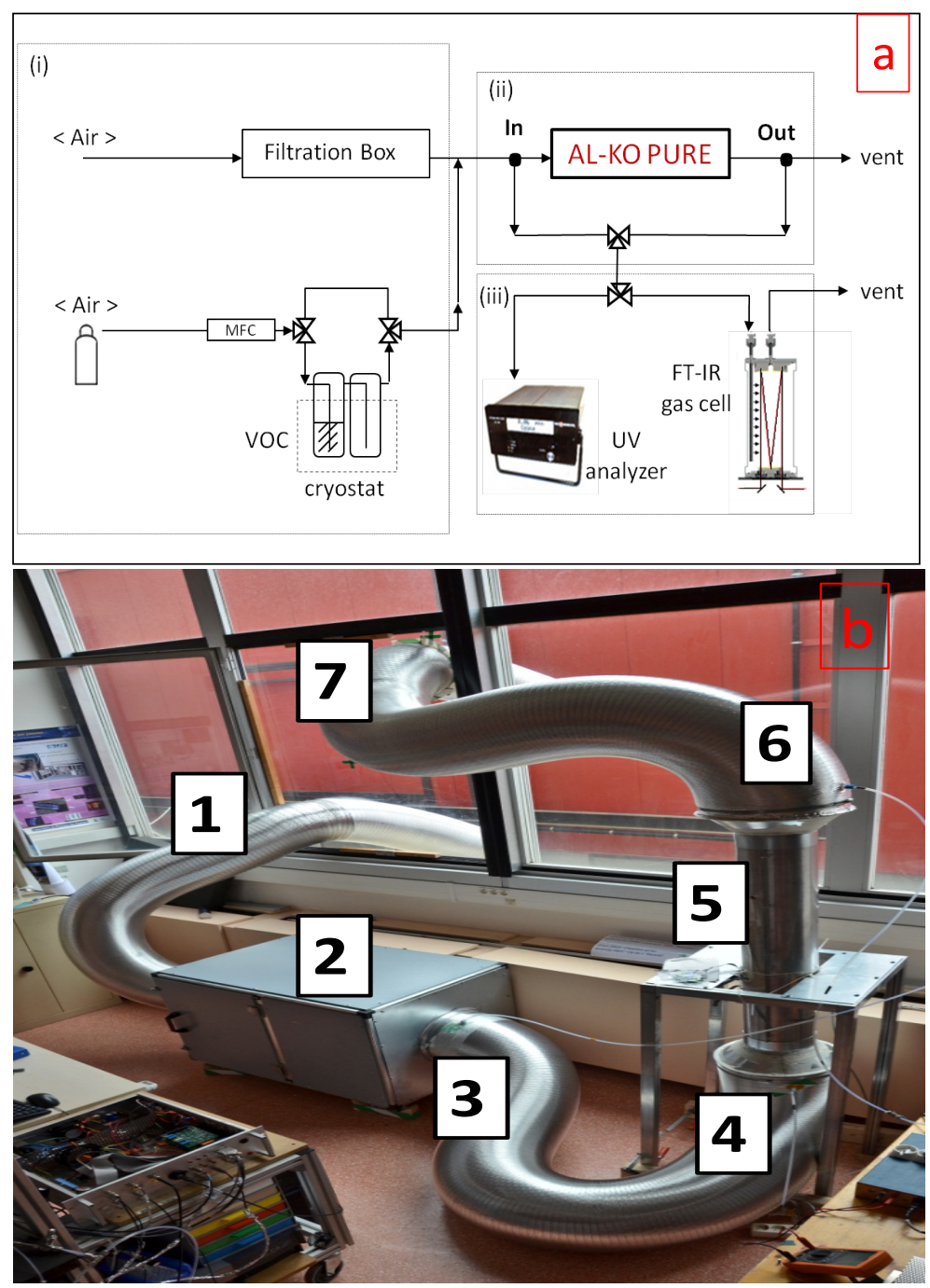

Figure 1. a) Schematic representation of the gas inlet system and experimental setup of the air treatment unit used for the campaign of VOC abatement; b) Photo of AL-KO PURE reactor.

the AL-KO PURE. Acetone is injected as following: a clean air (supplied by Air Liquide ALPHAGAZ1) bottle is used as carrying gas, which passes through the cryostat to transport the acetone to the filtrated ambient air and mixed up with it.

The model organic compounds used in this study are acetone and toluene (270725 and 244511-CHROMASOLV ${ }^{\circledR}$, for HPLC, $\geq 99.9 \%$ ) prepared by Sigma-Aldrich. Certified gas cylinders are supplied by Air Liquide. The regulation of the gas flow is insured by using the Brooks mass flow controllers.

\subsection{Analytical Device}

The real time detection and quantification of the gas phase species is performed using high resolution Nicolet 6700 Fourier Transform Infrared spectrometer (FTIR) equipped with a $10 \mathrm{~m}$ optical-path White cell and a cooled MCT (mercury cadmium telluride) detector. The cell is heated at $50^{\circ} \mathrm{C}$ to ensure a good regulation and to prevent adsorption onto the mirrors. Two spectra per minute are collected with Omnic software with 16 scans per spectrum and a spectral resolution of $0.5 \mathrm{~cm}^{-1}$. Detection limits of this analytical tool have been determined as two times the signal/noise ratio in the region of interest and are: $80 \mathrm{ppb}$ for acetone, $90 \mathrm{ppb}$ for toluene $15 \mathrm{ppb}$ for $\mathrm{O}_{3}$. Figure 2 shows the gas phase spectra acquired during calibration of the main detected species and the 


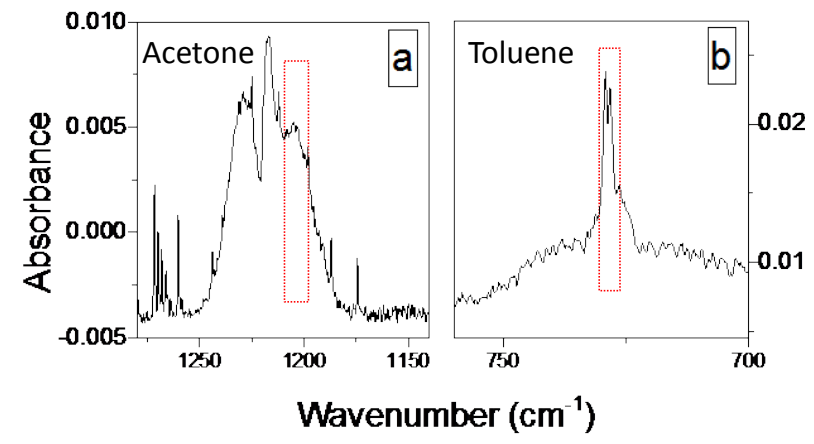

Figure 2. FTIR gas phase spectra acquired during calibration. The framed regions $(\mathrm{Q})$ were used to quantify the corresponding species. The figure shows (a) Acetone (1 ppm), (b) Toluene (1 ppm).

framed regions were used to quantify the corresponding species.

The ozone measurement was carried out with the analyzer "UV Precision Ozone Analyzer". The measuring range is of $0.002-900.00 \mathrm{ppm}$ with an error margin of $1 \%$.

\section{Results}

\subsection{Acetone Destruction}

\subsubsection{Fan Speed at $25 \%$}

We firstly tested an acetone concentration of $\sim 0.45 \mathrm{ppm}\left(1068 \mu \mathrm{g} / \mathrm{m}^{3}\right)$ which corresponds to about 7 times higher than the living room level. Figure 3 shows the acetone concentration measured at the inlet ([Acetone $]_{\text {In }}$ ) and outlet ([Acetone $]_{\text {Out }}$ ) of the reactor, as a function of time with a fan speed of $25 \%$ in the presence of a fresh sample of C1. In the first step, $0.46 \mathrm{ppm}$ of acetone is continuously sent into AL-KO PURE for a time period of 83 hours. In the second step, the inlet concentration is increased to $1.17 \mathrm{ppm}\left(2777 \mu \mathrm{g} / \mathrm{m}^{3}, 1.84 \mathrm{mmol} / \mathrm{h}\right)$ and is continuously sent into the reactor for 33 hours. Finally, in the third step, the inlet concentration is set back at $0.46 \mathrm{ppm}$ for approximately 10 hours.

Figure 3 shows that with an inlet concentration of $0.46 \mathrm{ppm}$, no acetone is detected for at least 83 hours. When the concentration increases to $1.17 \mathrm{ppm}$, acetone breaks through after 3 hours and slowly increases to reach a stable outlet concentration of $0.75 \mathrm{ppm}$. Decreasing the inlet concentration back to $0.46 \mathrm{ppm}$ results in no acetone at the reactor output, despite the former breakthrough of the molecule.

These results show that AL-KO PURE can completely destroy acetone, even when the VOC concentration is 7 times higher (0.46 ppm) than typical indoor air values. Furthermore, even when the inlet concentration increases to about 15 times $(1.17 \mathrm{ppm})$, almost half the molecules are still destroyed by the process. The difference in the inlet and outlet concentration of these three stages shows that AL-KO PURE could destroy $0.46 \mathrm{ppm}$ and $0.45 \mathrm{ppm}$ of acetone, out of $0.46 \mathrm{ppm}$ and $1.17 \mathrm{ppm}$, respectively.

The performance of the process can be determined by the acetone oxidation rate:

$$
\mathrm{V}_{A C}=\left(C_{A C, I n}-C_{A C, \text { Out }}\right) \times \frac{D_{2}}{V_{m}}
$$

where $V_{A c}$ (molecules/s) is acetone oxidized rate, $C_{A c, I n}(\mathrm{ppm})$ is the inlet concentration of acetone, $C_{A c \text {,out }}$ is the outlet concentration of acetone, $D_{2}$ is the flow rate of AL-KO PURE $\left(25 \%=38.45 \mathrm{~m}^{3} / \mathrm{h}=10.68 \mathrm{~L} / \mathrm{s}\right)$ and $V_{m}$ is molar volume $\left(25.465 \mathrm{~L} / \mathrm{mol}\right.$ at $25^{\circ} \mathrm{C}$ at 1 atmosphere of pressure).

It can be concluded that for initial concentrations of 0.46 and $1.17 \mathrm{ppm}, 0.20 \mu \mathrm{mol}$ and $0.18 \mu \mathrm{mol}$ of acetone are destroyed per second by AL-KO PURE.

\subsubsection{Fan Speed of $50 \%$}

Increasing the fan speed to $50 \%$ amounts to a flow of $97.9 \mathrm{~m}^{3} / \mathrm{h}$ and consequently a reduction in contact time by a factor 2. Using the same C1 sample, $0.6 \mathrm{ppm}$ of acetone is sent into the reactor with a fan speed of $50 \%$, and 


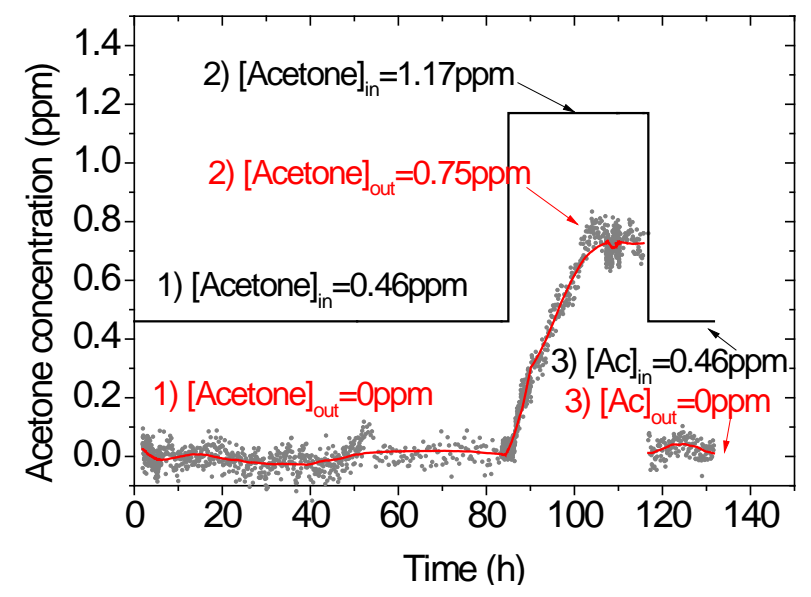

Figure 3. Acetone concentration measured at the inlet and outlet of the reactor for three input concentrations: (1) 0.46 ppm, (2) $1.17 \mathrm{ppm}$ and (3) $0.46 \mathrm{ppm}$, as a function of time, for a fan speed of $25 \%\left(38.42 \mathrm{~m}^{3} / \mathrm{h},\left[\mathrm{O}_{3}\right]=0.4 \mathrm{ppm}\right)$ and a new C1 catalyst.

result in a molar flow of $2.40 \mathrm{mmol} / \mathrm{h}$. The inlet and outlet concentrations throughout 130 hours are shown in Figure 4.

With an inlet concentration of $0.6 \mathrm{ppm}$, no acetone is detected at the reactor output during 100 hours of continuous treatment, after which, the outlet concentration slowly increases to reach a plateau at $0.46 \mathrm{ppm}$ for at least 30 hours. The acetone oxidation rate, determined by Equation (1) is equal to $0.14 \mu \mathrm{mol} / \mathrm{s}$ when the fan speed is of $50 \%$, compared to $0.2 \mu \mathrm{mol} / \mathrm{s}$ for a fan speed set at $25 \%$.

Further tests are conducted on the same C1 sample whereby $0.6 \mathrm{ppm}$ are first sent into AL-KO pure for 2.5 hours, after which the inlet concentration is increased to $0.9 \mathrm{ppm}$. Figure 5(a) shows the input and output acetone concentration measured from the inlet and outlet of the reactor, as a function of time for a fan speed of $50 \%$.

Despite the saturated surface (Figure 5(a)), only $0.46 \mathrm{ppm}$ and $0.78 \mathrm{ppm}$ acetone are detected out of the 0.60 and $0.92 \mathrm{ppm}$ sent onto the surface, respectively. When the same experiment is repeated on the saturated catalyst filter with an initial fan speed of $100 \%$ followed by a fan speed of $25 \%$, the same trend as Figure 5 (b) is observed, where $0.47 \mathrm{ppm}$ out of $0.82 \mathrm{ppm}$ and 0.27 out of $0.63 \mathrm{ppm}$ are detected at the reactor output. The oxidation rate of acetone $\left(\mathrm{V}_{\mathrm{Ac}}\right)$ for the results presented in Figure 5(a) and Figure 5(b) are summarized Table 2.

\subsection{Toluene Destruction}

Similarly to acetone, the abatement of different toluene concentrations for fan speeds of 25 and $50 \%$ are presented in the following section.

Figure 6 presents toluene concentration measured at the inlet and outlet of AL-KO PURE, as a function of time and with a fan speed of $25 \%$ for three inlet concentrations (1, 0.5 and $0.2 \mathrm{ppm})$ using a fresh C1 catalytic filter. In the first stage, the inlet toluene concentration was kept constant at $1.00 \mathrm{ppm}\left(4060 \mu \mathrm{g} / \mathrm{m}^{3}\right)$, no toluene has been detected at the outlet during 60 hours which is less than the case of acetone ( $83 \mathrm{~h}$ ). From 60 hours, the outlet concentration of toluene slowly increased and stabilized at $0.83 \mathrm{ppm}$, with $\Delta=0.17 \mathrm{ppm}$. As of 60 hours, the outlet concentration of toluene slowly increased and stabilized at $0.83 \mathrm{ppm}$, leading to a difference of 0.17 $\mathrm{ppm}$ between the inlet and outlet concentrations. When the inlet concentration is set to $0.5 \mathrm{ppm}\left(2030 \mu \mathrm{g} / \mathrm{m}^{3}\right)$, $0.28 \mathrm{ppm}$ are detected at the reactor output, which gives a difference $(\Delta)$ of about $0.22 \mathrm{ppm}$. Finally, when the inlet concentration is set to $0.2 \mathrm{ppm}\left(811 \mu \mathrm{g} / \mathrm{m}^{3}\right)$, no toluene is detected at the reactor output. Using Equation 1 , the toluene oxidation rate is about $0.087 \mu \mathrm{mol} / \mathrm{s}$ for a fan speed of $25 \%$, which is approximately half of the oxidation rate of acetone. Nonetheless, it can still be concluded that a complete destruction of the VOC can be reached ( $0.2 \mathrm{ppm})$, even in unfavorable conditions where the pollutant concentration is 4 - 40 times higher than the concentrations measured in real indoor air conditions. 


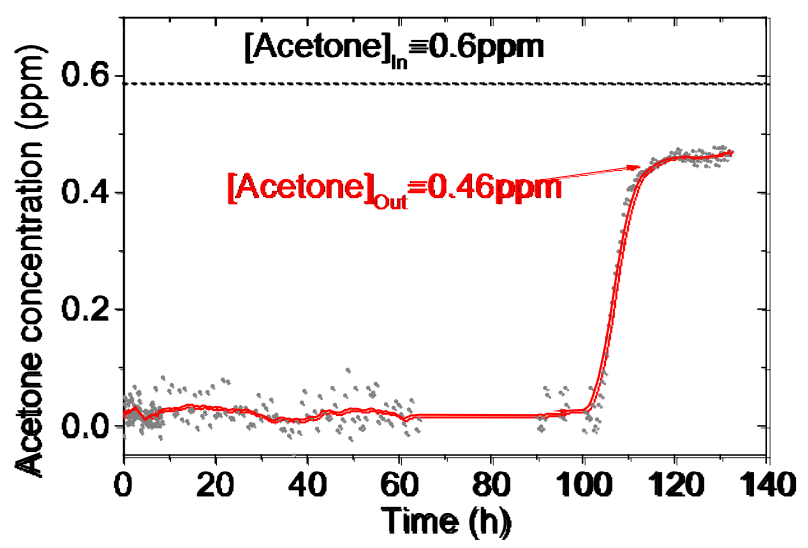

Figure 4. Acetone concentration measured at the inlet and outlet of the reactor for an input concentrations of $0.6 \mathrm{ppm}$ as a function of time, for a fan speed of $50 \%\left(97.9 \mathrm{~m}^{3} / \mathrm{h},\left[\mathrm{O}_{3}\right]=\right.$ $0.1 \mathrm{ppm})$.
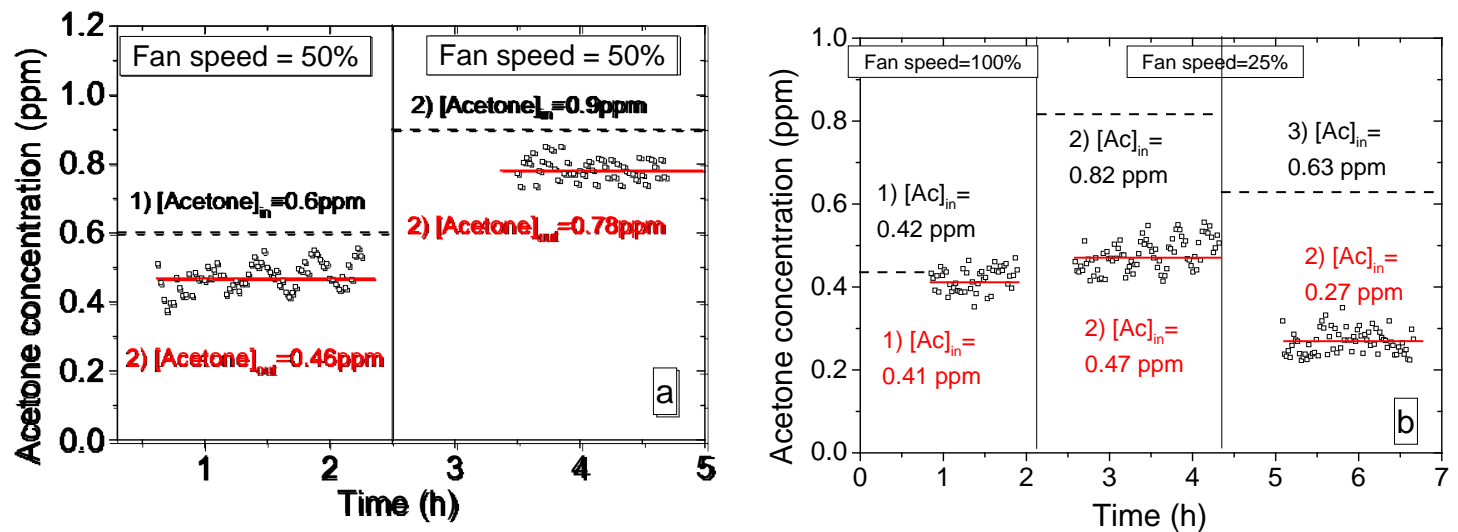

Figure 5. a) Acetone concentration measured at the inlet and outlet of the reactor for two input concentrations: (1) 0.6 ppm and (2) $0.9 \mathrm{ppm}$, as a function of time, for a fan speed of $50 \%\left(97.9 \mathrm{~m}^{3} / \mathrm{h},\left[\mathrm{O}_{3}\right]=0.1 \mathrm{ppm}\right)$; b) Acetone concentration measured at the inlet and outlet of the reactor for three input concentrations: (1) $0.42 \mathrm{ppm}$ and (2) $0.82 \mathrm{ppm}$ (3) $0.63 \mathrm{ppm}$, as a function of time, for a fan speed of $100 \%$ then $25 \%\left(100 \%: 257.49 \mathrm{~m}^{3} / \mathrm{h},\left[\mathrm{O}_{3}\right]=0.01 \mathrm{ppm}, 25 \%: 38.42 \mathrm{~m}^{3} / \mathrm{h},\left[\mathrm{O}_{3}\right]=0.4 \mathrm{ppm}\right)$.

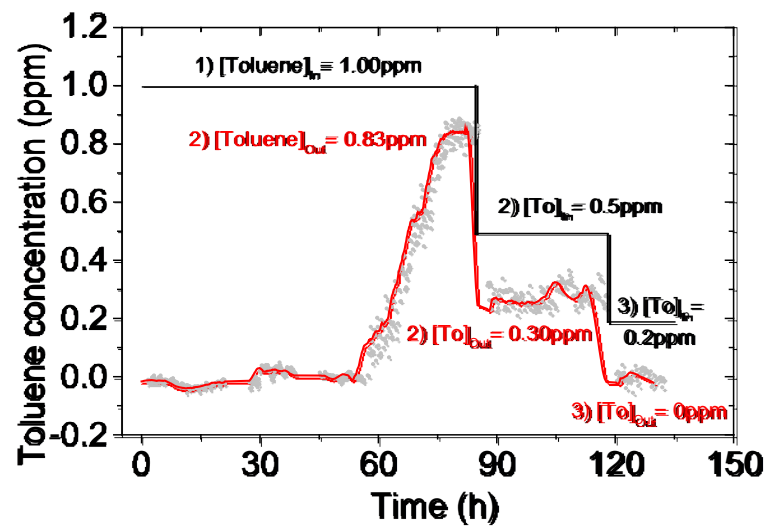

Figure 6. Toluene concentration measured at the inlet and outlet of the reactor for three input concentrations: (1) 0.83 ppm, (2) $0.5 \mathrm{ppm}$ and (3) $0.2 \mathrm{ppm}$, as a function of time, for a fan speed of $25 \%\left(38.42 \mathrm{~m}^{3} / \mathrm{h},\left[\mathrm{O}_{3}\right]=0.4 \mathrm{ppm}\right)$ and a new $\mathrm{C} 1$ catalyst. 


\subsection{Toluene and Acetone Simultaneous Removal}

Figure 7 presents acetone and toluene concentration measured at the inlet and outlet of AL-KO PURE, as a function of time and with a fan speed of $25 \%$. At the first stage, the input concentration of total VOCs was fixed $0.66 \mathrm{ppm}$ ([acetone] $=0.46 \mathrm{ppm}$ and [toluene] $=0.2 \mathrm{ppm}$ ), no acetone and toluene is detected for at least 60 hours. At the second stage, the inlet toluene concentration increased to $0.96 \mathrm{ppm}$ with [acetone] $=0.46 \mathrm{ppm}$ and [toluene] $=0.5 \mathrm{ppm}$, toluene breaks through after 3 hours and slowly increases to reach a stable outlet concentration of $0.16 \mathrm{ppm}$. However, in the case of toluene alone, this value is about $0.3 \mathrm{ppm}$. Toluene is more easily oxidized in presence of acetone than alone. The positive synergistic effect for acetone-toluene mixture may be linked to an increase of toluene adsorption on catalyst surface. Identically, T. Barakat et al. [15] show that the presence of butanone-toluene mixture, $\mathrm{Pd} / 5 \% \mathrm{~V}-\mathrm{TiO}_{2}$ showed a higher performance than in the elimination of butanone alone. Irusta et al. [16] show that the simultaneous feeding of toluene and MEK markedly increases the adsorption of both compounds (especially toluene) on $\mathrm{LaCoO}_{3}, \mathrm{LaMnO}_{3}, \mathrm{La}_{0.8} \mathrm{Sr}_{0.2} \mathrm{CoO}_{3}$ and $\mathrm{La}_{0.8} \mathrm{Sr}_{0.2} \mathrm{MnO}_{3}$.

\section{Conclusion}

The tests conducted on AL-KO PURE device on the two chosen VOCs, acetone and toluene, lead to the following conclusions:

- A complete destruction of the pollutants could be achieved at very low input energy of the plasma, even with VOC concentrations ten to forty times higher than typical indoor air values.

- The very different chemical families of the two VOCs show the wide range of applicability of AL-KO Pure.

- No ozone was detected at the reactor output for all the presented experiments, despite the high levels of RH, high flow rates, and long treatment phases.

- Even when the filter is saturated, the treatment unit can still destroy the pollutants with oxidation rate depending upon the class of molecules but not on their concentration or residence time.

- If left long enough, the plasma is able to completely regenerate the surface/filter from adsorbed species.

Table 2. Summary of acetone oxidation rate for the different inlet concentrations in Figure 5(a) and Figure 5(b).

\begin{tabular}{ccccc}
\hline Fan speed & $50 \%$ & & $25 \%$ & 0.82 \\
$\mathrm{C}_{\text {in }}(\mathrm{ppm})$ & 0.90 & 0.60 & 0.47 & 0.63 \\
$\mathrm{C}_{\text {out }}(\mathrm{ppm})$ & 0.78 & 0.46 & 0.15 & 0.16 \\
$\mathrm{~V}_{\mathrm{Ac}}(\mu \mathrm{mol} / \mathrm{s})$ & 0.12 & 0.14 & & 0.27 \\
\hline
\end{tabular}

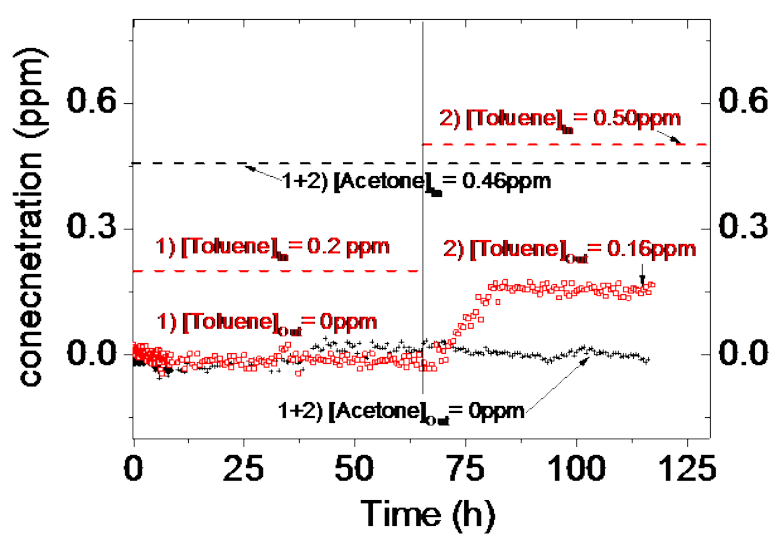

Figure 7. Acetone and toluene concentration measured at the inlet and outlet of the reactor for two input concentrations: (1) $0.66 \mathrm{ppm}$ ([acetone] $=0.46 \mathrm{ppm}$ and [toluene $]=0.2 \mathrm{ppm})$, $(2)$ $0.96 \mathrm{ppm}$ ([acetone] $=0.46 \mathrm{ppm}$ and [toluene $]=0.5 \mathrm{ppm}$ ), as a function of time, for a fan speed of $25 \%\left(38.42 \mathrm{~m}^{3} / \mathrm{h}\right.$, [O3] = $0.4 \mathrm{ppm}$ ) and a new C1 catalyst. 
- The availability for the simultaneous removal of both pollutants, acetone and toluene, has been proved. The positive synergistic effect for acetone-toluene mixture promotes toluene destruction.

\section{Acknowledgements}

The authors gratefully acknowledge Plasma@par, AL-KO Therm and DGA for financial support.

\section{References}

[1] Pitts, B.J.F. and Pitts, J.N. (2000) Chemistry of the Upper and Lower Atmosphere: Theory, Experiments and Applications. Academic Press, New York.

[2] Spengler, J. and Sexton, K. (1983) Indoor Air Pollution: A Public Health Perspective. Science, 221, 9-17.

[3] Zhang, Y. and Xu, Y. (2003) Characteristics and Correlations of VOC Emissions from Building Materials. International Journal of Heat and Mass Transfer, 46, 4877-4883. http://dx.doi.org/10.1016/S0017-9310(03)00352-1

[4] Publications du gouvernement du Canada (2014) Screening Assessment-Acetone. Sepember 2014.

[5] Wang, B., Lee, S.C. and Ho, K.F. (2007) Characteristics of Carbonyls: Concentrations and Source Strengths for Indoor and Outdoor Residential Microenvironments in China. Atmospheric Environment, 41, 2851-2861. http://dx.doi.org/10.1016/j.atmosenv.2006.11.039

[6] Van Durme, J., Dewulf, J., Sysmans, W., Leys, C. and Van Langenhove, H. (2007) Abatement and Degradation Pathways of Toluene in Indoor Air by Positive Corona Discharge. Chemosphere, 68, 1821-1829. http://dx.doi.org/10.1016/j.chemosphere.2007.03.053

[7] Baelum, J., Lundqvist, G.R., Mølhave, L. and Andersen, N.T. (1990) Human Response to Varying Concentrations of Toluene. International Archives of Occupational and Environmental Health, 62, 65-71. http://dx.doi.org/10.1007/BF00397850

[8] Kang, S.-K., Rohlman, D.S., Lee, M.-Y., Lee, H.-S., Chung, S.-Y. and Anger, W.K. (2005) Neurobehavioral Performance in Workers Exposed to Toluene. Environmental Toxicology and Pharmacology, 19, 645-50. http://dx.doi.org/10.1016/j.etap.2004.12.049

[9] Holzer, F. (2002) Combination of Non-Thermal Plasma and Heterogeneous Catalysis for Oxidation of Volatile Organic Compounds Part 1. Accessibility of the Intra-Particle Volume. Applied Catalysis B: Environmental, 38, 163-181. http://dx.doi.org/10.1016/S0926-3373(02)00040-1

[10] Jia, Z., Vega-Gonzalez, A., Ben Amar, M., Hassouni, K., Tieng, S., Touchard, S., Kanaev, A. and Duten, X. (2013) Acetaldehyde Removal Using a Diphasic Process Coupling a Silver-Based Nano-Structured Catalyst and a Plasma at Atmospheric Pressure. Catalysis Today, 208, 82-89. http://dx.doi.org/10.1016/j.cattod.2012.10.028

[11] Thevenet, F., Sivachandiran, L., Guaitella, O., Barakat, C. and Rousseau, A. (2014) Plasma-Catalyst Coupling for Volatile Organic Compound Removal and Indoor Air Treatment: A Review. Journal of Physics D: Applied Physics, 47, 224011. http://dx.doi.org/10.1088/0022-3727/47/22/224011

[12] Vandenbroucke, A.M., Morent, R., De Geyter, N. and Leys, C. (2011) Non-Thermal Plasmas for Non-Catalytic and Catalytic VOC Abatement. Journal of Hazardous Materials, 195, 30-54. http://dx.doi.org/10.1016/j.jhazmat.2011.08.060

[13] Dong, B. and Ginsterblum, S. (2014) Air Cleaning Device. Patents, No. WO2013174467.

[14] Czejka, S., Dong, B. and Ginsterblum, S. (2014) Indoor Air Purification Apparatus. Patents, No. WO2014102398.

[15] Barakat, T., Rooke, J.C., Cousin, R., Lamonier, J.-F., Giraudon, J.-M., Su, B.-L. and Siffert, S. (2014) Investigation of the Elimination of VOC Mixtures over a Pd-Loaded V-Doped TiO2 Support. New Journal of Chemistry, 38, 2066. http://dx.doi.org/10.1039/c3nj01190a

[16] Irusta, S., Pina, M.P., Menéndez, M. and Santamaría, J. (1998) Catalytic Combustion of Volatile Organic Compounds over La-Based Perovskites. Journal of Catalysis, 179, 400-412. http://dx.doi.org/10.1006/jcat.1998.2244 